\title{
BMJ Open Foundation Year 2 doctors' reasons for leaving UK medicine: an in-depth analysis of decision-making using semistructured interviews
}

\author{
Samantha E Smith, ${ }^{1}$ Victoria R Tallentire, ${ }^{1}$ Lindsey M Pope, ${ }^{2}$ Anita H Laidlaw, ${ }^{3}$ \\ Jill Morrison ${ }^{4}$
}

To cite: Smith SE, Tallentire VR, Pope LM, et al. Foundation Year 2 doctors' reasons for leaving UK medicine: an in-depth analysis of decisionmaking using semistructured interviews. BMJ Open 2018;8:e019456. doi:10.1136/ bmjopen-2017-019456

- Prepublication history for this paper is available online. To view these files, please visit the journal online (http://dx.doi. org/10.1136/bmjopen-2017019456).

Received 4 September 2017 Revised 3 November 2017 Accepted 17 November 2017

Check for updates

${ }^{1}$ Centre for Medical Education, University of Edinburgh,

Edinburgh, UK

${ }^{2}$ Gilmorehill Campus, University of Glasgow Medical School,

Glasgow, UK

${ }^{3}$ Population and Behavioural Health Sciences, Medical and Biological Sciences, University of St Andrews, St Andrews, UK

${ }^{4}$ General Practice and Primary Care, University of Glasgow Medical School, Glasgow, UK

Correspondence to Dr Samantha E Smith;

Sam.Smith@ed.ac.uk

\section{ABSTRACT}

Objectives To explore the reasons that doctors choose to leave UK medicine after their foundation year two posts.

Setting All four regions of Scotland.

Participants Foundation year two doctors (F2s) working throughout Scotland who were considering leaving UK medicine after foundation training were recruited on a volunteer basis. Maximum variation between participants was sought.

Primary and secondary outcome

measures Semistructured interviews were coded using template analysis. Six perspectives, described by Feldman and $\mathrm{Ng}$, were used as the initial coding template. The codes were then configured to form a framework that explores the interplay of factors influencing Foundation Year 2 (F2) doctors' decisions to leave UK medicine.

Results Seventeen participants were interviewed. Six perspectives were explored. Structural influences (countrywide and worldwide issues) included visas, economic and political considerations, structure of healthcare systems and availability of junior doctor jobs worldwide. Organisational influences (the National Health Service (NHS) and other healthcare providers) included staffing and compensation policies, the working environment and the learning environment. Occupational influences (specific to being a junior doctor) comprised the junior doctor contract, role and workload, pursuit of career interests and the structure of training. Work group influences (relationships with colleagues) included support at work, task interdependence and use of locums. Personal life influences consisted of work-life balance, and support in resolving work-life conflict. The underlying theme of 'taking a break' recurred through multiple narratives.

Conclusions F2s give reasons similar to those given by any professional considering a change in their job. However, working within the NHS as an F2 doctor brought specific challenges, such as a need to make a choice of specialty within the F2 year, exposure to workplace bullying and difficulties in raising concerns. Despite these challenges, most F2s did not view their decision to leave as a permanent job change, but as a temporary break from their current working lives.
Strengths and limitations of this study

This study explores the in-depth views of Scotlandbased Foundation Year 2 doctors regarding their training experience and their ideas about junior doctor jobs abroad. It explores their explicit reasons for leaving, as well as some factors known to increase job mobility, in order to uncover some of the hidden reasons for junior doctors leaving UK medicine.

- This study fills a gap in the literature, as there have been few studies exploring the subject, and no previous qualitative studies examining this issue.

- A constructivist approach was used, and therefore the results do not attempt to predict the future, but instead explore the intricacies of decision-making, and provide a springboard for further areas of research.

- The foundation year two doctors (F2s) had a broad range of specialty interests, range of destination countries, country of origin, and both genders were represented. However, the age range was narrow and all F2s were based in Scotland. The results may therefore be transferable to other contexts but are not generalisable.

While every attempt was made to put participants at ease, and create a non-threatening environment, the F2s may have wanted to present a certain image of themselves to the researcher, and may have chosen to hide some of their reasons for leaving accordingly.

\section{INTRODUCTION}

The Foundation Year 2 (F2) Career Destination Report 2016 showed that only $50.4 \%$ of UK F2 doctors progressed to UK specialty training, a year-on-year decrease from $71.3 \%$ in $2011,67.0 \%$ in $2012,64.4 \%$ in $2013,58.5 \%$ in 2014, and 52.0\% in 2015. ${ }^{1}$ Between 2010 and 2013, the numbers of UK doctors applying for a General Medical Council certificate of good standing, enabling them to work abroad, increased by over $16 \%$ from 4080 to 4741 . $^{2}$ The F2 Career Destination Report provides further 
evidence that many of these applicants are F2 doctors: in $2015,10.8 \%$ had secured or intended to secure employment as a doctor outside the UK. ${ }^{1}$

As F2 doctors move abroad, take career breaks or leave the profession altogether, UK medicine is left in a state of crisis, with $12 \%$ of general practitioner (GP) specialty training posts unfilled in $2014^{3}$ and $17 \%$ of Scottish GP practices reporting at least one vacancy. ${ }^{4}$ The Scottish Government have recently announced that there will be 100 new GP training places this year, ${ }^{5}$ but given the large numbers of foundation year two doctors (F2s) leaving the UK, it may not be possible to fill these places. The detrimental effect of the exodus might be mitigated to some extent if many of the doctors who leave after foundation training subsequently return to UK medicine. However, evidence suggests this is often not the case: a questionnaire study of UK doctors who had settled permanently in New Zealand showed that only 30\% had originally intended to stay long term, suggesting that despite the majority of doctors having intentions to return to the UK when they initially move abroad, many do not do so. ${ }^{6}$

There is a surprising lack of research into the reasons why doctors decide to leave UK medicine. Two studies have attempted to gain such insights using questionnaires. Moss et al sent a postal questionnaire to a group of UK graduates in 1999, approximately a year after graduation. ${ }^{7}$ Of the 4221 graduates, 2727 responded. Sixteen per cent of respondents indicated that they were probably or definitely not going to continue to practise medicine in the UK. The main reasons cited included working conditions and lifestyle factors. ${ }^{7}$ Sharma et al sent a questionnaire to UK doctors who had settled in New Zealand in 2012. ${ }^{6}$ Out of 419 doctors sent the questionnaire, 282 responded. The majority of respondents $(69 \%)$ stated that their reason for moving was for a clinical job. ${ }^{6}$ Other reasons included seeking other work, for a holiday, to spend time with family or friends, better lifestyle in New Zealand, or disillusioned with the National Health Service (NHS) or with life in the UK. Thus, the reasons for moving abroad were similar to those found in 1999, relating to perceived poorer working conditions in the UK and perceived improved lifestyle abroad.

These studies were carried out prior to the sharp increase in the proportion of $\mathrm{F} 2$ doctors opting to leave UK training. It is therefore timely to re-examine this significant and growing issue, to understand more fully the reasons underlying the increased numbers of F2 doctors leaving UK medicine. Furthermore, there have not been any qualitative studies which have aimed to characterise the reasons for F2 doctors leaving UK medicine (beyond the short generic stems used in questionnaire-based studies), or which have investigated the relative influences of the salient factors on doctors' decisions to leave.

\section{Research aims}

The aim of this interview study was to explore F2 doctors' reasons for leaving UK medicine, in order to better understand how they might be encouraged to stay.

\section{METHODS}

\section{Philosophical assumptions}

This research required a constructivist approach in order to explore in detail the decision-making processes of $\mathrm{F} 2$ doctors. As per Guba and Lincoln's description of the metaphysical paradigms, the following philosophical assumptions were made: (1) the ontology is relativist (there is no objective reality); (2) the epistemology is transactional and subjectivist (truth is constructed by the researchers through interactions with the world); (3) the methodology is interpretative and explanatory, rather than experimental. ${ }^{8}$ The result of this research will not be a definitive explanation of why F2 doctors leave UK medicine, but will instead be an exploration of the myriad of factors influencing decision-making.

\section{Framework}

While there have been limited studies examining the reasons that F2 doctors choose to leave UK medicine, there has been research examining 'career mobility' versus 'career embeddedness' in professionals in general. ${ }^{9}$ Feldman and $\mathrm{Ng}^{9}$ examined the pertinent literature and assimilated it into six perspectives that influence career mobility versus embeddedness. In brief, these perspectives were as follows:

1. the structural perspective: macroeconomic factors and social and legal factors, for example, the number and quality of jobs available; UK-wide or worldwide factors which are not specific to a single profession;

2. the organisational perspective: organisational staffing and compensation policies; any organisational policy that affects all the workers within that organisation;

3. the occupational perspective: salary and workload; organisational policies which affect a specific occupational group;

4. the work group perspective: social connections and interactions that professionals have, both within their own organisation and between different organisations;

5. the personal life perspective: the impact that the nonwork part of a professional's life has on their decision to move (such as friends and family); includes worklife balance, and how the impact of work on personal life influences an individual's decision-making;

6. the personality perspective: the impact of personality types such as the 'big five' or attachment styles on career mobility versus embeddedness. ${ }^{9}$

Feldman and Ng's six perspectives represent an appropriate starting point for this study, because the factors above resonate with both the authors' experiences within medicine and the previous research detailed above. ${ }^{67}$

A pictorial representation of the six perspectives is shown in figure 1 .

\section{Data collection}

Participant recruitment

At the time of this research, there were contentious proposed changes to junior doctor contracts in England 
Structural perspective:

Macroeconomic conditions

Social and legal factors

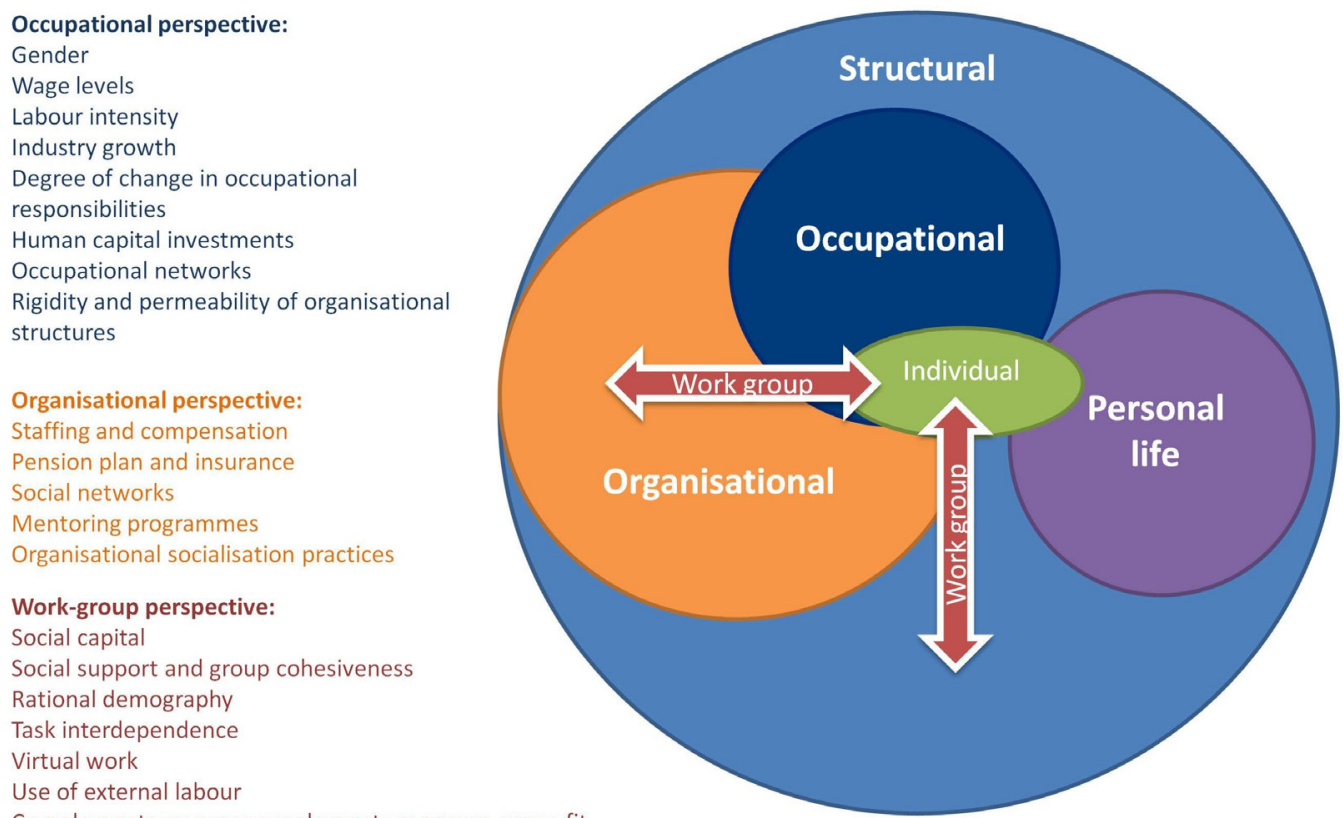

Complementary versus supplementary person-group fit

Personal life perspective:

Amount and predictability of time demands

Support in resolving work-life conflict

Family and friendship networks

Figure 1 The six perspectives that influence career mobility versus embeddedness.

resulting in strike action by junior doctors. ${ }^{10}$ These recently proposed contractual changes would inevitably have been the focus of conversation had the study recruited doctors currently working in England. For these reasons, this study focused on F2 doctors currently working in Scotland.

Doctors who planned to leave UK medicine on completion of foundation training were recruited on a volunteer basis. Participants were invited via a notice in the Scotland-wide foundation bulletin, a message in the foundation trainee e-portfolio, a notice in the British Medical Association Scotland junior doctors committee newsletter, opportunistically in the workplace and at medical education conferences, using social media and through snowball sampling. ${ }^{11}$ Volunteers who showed interest in participating were sent information about the study and then decided whether or not to participate. Those who did participate completed consent forms.

Maximum variation was sought, with the aim of including participants from all Scottish deaneries, both genders, a variety of proposed destinations, a variety of nationalities, a variety of career interests and as broad an age range as possible. While acknowledging that saturation is always a 'matter of degree, ${ }^{12}$ data collection ceased when the new data generated did not add to the overall framework.

\section{Semistructured interviews}

A single researcher (SES) conducted online-video semistructured interviews with participants to explore their reasons for leaving UK medicine. The researcher is a female GP with a medical education doctorate, with experience in qualitative research interviewing both during her doctorate and subsequently. Prior to interview commencement, participants were informed of the researcher's background, purpose of the research, and were invited to ask any questions.

The interview structure was based on the factors identified by Feldman and Ng. ${ }^{9}$ During the interviews, particular attention was paid to eliciting rich descriptions of the decision-making process including the factors involved and the ways in which salient factors were identified and assimilated. Data analysis was carried out in tandem with collection, in order that new themes could be expanded and explored in subsequent interviews. Interviews were audio-recorded, transcribed verbatim and anonymised. Field notes were taken during interviews when required. Participants received a $£ 20$ Amazon voucher as recompense for their time.

\section{Ethical considerations}

Data storage: Participant names were only used when absolutely essential (eg, on consent forms), and were not used to identify files or recordings. All data, including audio recordings and transcriptions, were deidentified 
and stored in a separate location from any identifiable data on a secure, password-protected computer. Audio files were deleted once transcription was complete and individuals were assured of total anonymity.

Impact on individuals: Participants were reminded at the start of the interview that they may terminate the interview and withdraw from the study at any point without penalty. The main researcher (SES) has significant experience in various interview-based techniques. In addition, through her GP training, she has learnt to identify emotional cues and non-verbal manifestations of distress. We recognised that some participants might find discussions regarding their future or the prospect of leaving medicine confronting and upsetting. Appropriate support was offered to any doctors who become distressed during data collection and during debrief they were provided details of external sources of support.

The team ensured the interviewer was not in a position of power over any participant, for example, as an educational or research supervisor.

\section{Data analysis}

Initial data analysis was undertaken by SES using template analysis. ${ }^{13}$ In template analysis, the codes are generated both 'a priori' and inductively during the analysis. ${ }^{13}$ The framework provided by Feldman and Ng's literature search $^{9}$ was used for the initial template, but this was later modified and amplified by the data. Data were coded in Microsoft Word by SES then reviewed by one of three additional researchers to check for other interesting codes and themes that may not otherwise have been identified. The codes were renamed, reshuffled and redefined to ensure resonance with the data and overall coherency. The codes were then configured to form a framework that explores the interplay of factors influencing F2 doctors' decisions to leave UK medicine.

\section{RESULTS}

\section{Participants}

Nineteen interviews were scheduled and 17 took place (two participants failed to respond after initially showing interest). Of the 17 participants, 12 were women and five were men. Six were from the South East region, five from the East, three from the North and three from the West. Five planned to go to Africa (South Sudan, Uganda, South Africa), 11 planned to go to Australia or New Zealand and one planned to go to Europe (Germany). Eight planned to ultimately apply for medical specialties, three to surgery, one to psychiatry, two to obstetrics and gynaecology and three were undecided. Eight were Scottish, three were English, one was Northern Irish, one was Welsh, one was from Africa, one from Singapore, one from Malaysia and one from Hong Kong. All participants were aged 24-27 and all had studied medicine in the UK.

\section{Interviews}

All interviews were conducted online with video (FaceTime or Skype). Participants were interviewed in their own homes. Only the interviewer and the participant were present. Interviews lasted, on average, $42 \mathrm{~min}$ (28-65 min). Repeat interviews were not required.

\section{Coding framework}

The resultant coding framework is explained below. The personality perspective is not included in this paper, as it is not amenable to intervention. Any themes deemed not amenable to intervention (eg, climate, influence of friends and family or personal interests) are also excluded from this analysis. Themes that discouraged doctors from visiting certain countries (eg, needing extra exams or concerns about personal safety) were also not included in this analysis.

\section{Structural perspective}

Visas: F2s reported that Australia and New Zealand made it relatively easy for them to navigate the process of obtaining a visa. However, F2s who were non-UK citizens reported that UK visa made it more difficult for them to stay in the UK:

....if I wanted to do that [locum for six months in the UK], I couldn't, I need an actual job that I'm doing for the whole year to be able to stay. (P12, a non-UK citizen)

Economic and political considerations: At the time of this research, Scotland was holding a referendum regarding whether it should become independent of the UK. Financial uncertainty brought about by the Scottish independence referendum was cited as a reason to move abroad now. Some participants stated that if Scotland were to become independent, this might put them off returning to the UK.

If things stayed as they are just now, I would come back quite easily. But, if Scotland was to become independent that would be a trickier one. Where are they going to get the money from to fund the budget?... So, if that was to happen then it would be a bit more difficult to come back. (P3)

During the course of the research, the UK also held a referendum regarding its independence from the European Union (EU). The UK's exit from the EU was seen as a potential future barrier to working in EU countries, but did not influence the decision to go now.

I was shocked, to see the news [about the UK's decision to leave the EU]. But I guess it won't happen for another twoyears, at least. And hopefully that wouldn't affect my chance of finding a job, because I'm going now, instead of in two years. Where I think for people after me, then it might not be as easy actually, to find a job abroad, especially in Europe. (P14)

The full list of subthemes explored within the structural perspective is shown in table 1 . In table 1 and the subsequent tables, many of the subthemes directly correlate with the Feldman and Ng's framework. Those that 
Table 1 Structural perspective

$\begin{array}{lll}\text { Subtheme Details Illustrative quote } & \text { Dets }\end{array}$

Moving to another country in general
Visas*

Economic and political considerations
F2s reported that Australia and New Zealand made it relatively easy for them to navigate the process. UK visa rules were cited as a reason for non-UK citizens leaving the UK.

The Scottish independence referendum Financial uncertainty brought about by the recent Scottish independence referendum was cited as a reason to move abroad now. Some participants stated that if Scotland were to become independent, this might put them off returning to the UK.

\section{Britain's exit from the EU}

Britain's exit from the EU was seen as a potential future barrier to working in EU countries, but did not influence the decision to go now.
Illustrative quote

... if I wanted to do that [locum for six months in the UK], I couldn't, I need an actual job that I'm doing for the whole year to be able to stay.' (P12, a non-UK citizen)

'If things stayed as they are just now, I would come back quite easily. But, if Scotland was to become independent that would be a trickier one. Where are they going to get the money from to fund the budget?. ... So, if that was to happen then it would be a bit more difficult to come back.' (P3)

'I was shocked, to see the news [about the UK's decision to leave the EU]. But I guess it won't happen for another twoyears, at least. And hopefully that wouldn't affect my chance of finding a job, because I'm going now, instead of in twoyears. Where I think for people after me, then it might not be as easy actually, to find a job abroad, especially in Europe.' (P14)

\section{Moving to another country as a doctor}

$\begin{array}{ll}\text { Structure of healthcare } & \text { Certain healthcare systems, such as } \\ \text { systems* } & \text { Malaysia, Singapore, Canada and the } \\ & \text { USA, were seen as undesirable to work in. } \\ & \text { Reasons included long working hours, poor } \\ \text { training opportunities, rural placements and } \\ \text { health inequality. Some F2s felt that different } \\ \text { healthcare systems helped the public to } \\ \text { value healthcare professionals more. }\end{array}$

Availability and quality of junior doctor jobs in the world

\section{Many of the F2s had found it relatively easy} to get the job of their choice, and quantity of jobs in their destination country was not seen as an issue. Some F2s felt that the quality of available jobs in their destination country was low, but this was not a big concern, as their reasons for leaving were not necessarily to seek quality training opportunities.

'I suppose medics are viewed in a better way [in Australia], just more respect. The patients probably pay a bit of insurance and they do have to take accountability for their own health care and that way they do then value all the healthcare professionals more, not just the medics.' (P6) 'Frankly, I didn't want to work the 100 hour weeks that they do in Singapore.' (P10)

'My impression is that basically you end up with the jobs that no-one else wants from Australia or New Zealand. Quality-wise you're probably ending up in a job that is less good than you would get in the UK but as a friend of mine put it to me you're not going there really for the clinical exposure... most people are going there because they want a different experience.' (P1)

\section{The typical NHS patient was viewed by} some as a 'chronic disease patient', with 'I'm really hoping that I get a snake bite, just because that'll be the moment that l've made it in many climate and lifestyle-related conditions. Australia. I know there's quite interesting cultural Going abroad was, for some, a way of experiencing different types of medicine.
How often have you stayed overtime and got no...no one thanks you for it. You get upset because you're hungry, tired, haven't gone to the toilet and you're never getting paid for it. (P10)

Working environment: The working environment and staff morale within the NHS were described as poor.

There's just a lot of kind of negativity in the NHS at the moment amongst junior doctors and I don't know if it's become a bit of a culture thing as well... We have great resources, a great structure, but something at the moment isn't working. We don't have 
enough money or we don't have enough doctors and it's just a horrible environment to work in I think. (P8)

In contrast, F2s imagined that the working environment in Australia and New Zealand was more pleasant.

The Australian people's personalities are very relaxed and very chilled, so a lot of people have said that that it's a nice environment to work in. In that sense I think it could differ between that and the UK. (P11)

Non-handoverable jobs: F2s described staying late at work for jobs that were 'non-handoverable'. These were jobs that were not urgent but they did not feel they could hand over to the next shift.

It's things like ordering bloods for tomorrow. Things you know that should have been done during the day. But sometimes, you're just so busy, it doesn't get done. (P10)

Raising concerns: F2s were unsure about how to raise concerns and were worried that they might be penalised for doing so.

How are you supposed to give any of this feedback to the top people, because where on earth are they? I think also sometimes you're worried if you had a concern and you expressed it, that number one, it would fall on deaf ears, and also would you be getting into trouble for expressing concerns? (P9)

Formal teaching: Australia had a reputation for providing more formal teaching than that which is offered in the UK.

One of my friends who is working out in Perth [Australia], has said actually she has like hourly sessions kind of every other week where she'll get bedside teaching. That's way above and beyond what I've had. I don't think I've had bedside teaching beyond what happens on a ward round. (P13)

Mentorship: Most of the F2s did not have a mentor but would like to have had one.

My consultant [in a previous job] was very good in encouraging and looking at options and she was probably the person who gave me the most advice about careers. I found that immensely useful, so I think to have some kind of continuity with someone who could be a mentor would have been probably very helpful. (P8)

Careers advice: Some F2s stated that they had received little or no career advice.

I think most of the time people expect you to just figure out on our own what you want to do and get the advice that you want on your own. (P12)

Further examples are given in table 2.

\section{Occupational perspective}

Salary: An increased salary abroad was seen as a "nice bonus', but many of the F2s did not know what their salary would be, and some were going to be working on a volunteer basis. In general, they did not express a desire to go abroad for better pay, but did express a desire to be paid fairly for the work they did.

Junior doctor contracts: The proposed changes to junior doctor contracts in England provoked mixed emotions among the F2s.

I think if I worked down there [in England] I'd be totally disheartened and wouldn't really want to continue. Sometimes I think I probably wouldn't want to do this job if I was paid any less... And it'll definitely change my perception if I come back and Scotland's gone the same way, what will I do? (P2)

I always wanted to work in London, so if I was applying for CMT1, I would have liked to have apply down South. [But] there was a lot of uncertainty and there's still a lot of uncertainty now about what the contracts are going to be like. I think they have started releasing the provisional contracts now and they look terrible. You've been paid less and you're working a lot more and you're working one in two weekends. It didn't seem like a good thing to trade rather than working somewhere where there is a good work life balance and sunshine and people appreciate what you do for a living in Australia-why would I want to move to England? (P12)

Transferability of skills: F2s described the development of transferable skills which would help them in their future jobs.

I find now I'm less afraid of difficult conversations with families or patients. You have to be better at prioritisation and organising your time. Also trying to delegate to other people and knowing when it's appropriate to call for senior help. (P1)

However, some F2s did not feel that their skill development had adequately prepared them to enter specialty training directly.

When I see people go and start their CMT [core medical training], they cover CCU [the coronary care unit] and renal on their nightshift. It's funny because at the moment I'm the one calling them about this abnormal ECG [electrocardiogram], but then you think, God, in four months' time I'm the one who is getting called... that sounds awful. I think maybe I am just not quite ready to go into CMT yet. (P9)

Further study and research: Some of the F2s planned to spend part of their time after F2 completing further study or research.

I am spending the first three months doing a tropical medicine diploma... (P5) 
Table 2 Organisational perspective

\begin{tabular}{|c|c|c|}
\hline Subtheme & Details & Illustrative quote \\
\hline \multicolumn{3}{|c|}{ Staffing and compensation policies } \\
\hline Location of jobs ${ }^{\star *}$ & $\begin{array}{l}\text { Current staffing policies result in F2s not necessarily } \\
\text { working in the region of the UK in which they would } \\
\text { prefer to live. }\end{array}$ & $\begin{array}{l}\text { 'As much as I love being here, I feel it is not a very attractive } \\
\text { region within the UK. It's probably the bottom of the pile.' } \\
\text { (P6) }\end{array}$ \\
\hline Rota gaps ${ }^{\star *}$ & $\begin{array}{l}\text { Most of the F2s had worked in jobs in which there } \\
\text { were rota gaps, and most had been asked to } \\
\text { increase their hours to fill these gaps. }\end{array}$ & $\begin{array}{l}\text { 'All my previous rotas, they've never been fully staffed... we } \\
\text { were three down at one point, and we just had to cover the } \\
\text { bulk of that. And we sent emails saying, this is so unsafe, bu } \\
\text { you don't really get very far with that.' (P4) }\end{array}$ \\
\hline Rota policies ${ }^{\star *}$ & $\begin{array}{l}\text { In Australia, it was possible to pair rotas with a } \\
\text { partner. }\end{array}$ & $\begin{array}{l}\text { 'One perk of Australia, the pairing, or more consideration to } \\
\text { the rota. They're not fully linking mine, but they're going to } \\
\text { match when we're working weekends.' (P15) }\end{array}$ \\
\hline Perks & $\begin{array}{l}\text { Australian organisations were thought to have good } \\
\text { perks compared with the NHS, which contributed to } \\
\text { the sense of feeling valued. Having somewhere to } \\
\text { go to during breaks, such as a doctor's mess, was } \\
\text { felt to be important. }\end{array}$ & $\begin{array}{l}\text { 'It's kind of hard to take a break and dissociate yourself from } \\
\text { work when there's nowhere to go.' (P2) }\end{array}$ \\
\hline
\end{tabular}

\section{Working environment}

Feeling valued Many of the F2s felt that Australian and New Zealand organisations valued their staff more than the NHS did.
'How often have you stayed overtime and got no...no one thanks you for it. You get upset because you're hungry, tired, haven't gone to the toilet and you're never getting paid for it.' (P10)

'Non-handoverable jobs'** F2s described staying late at work for jobs that were 'It's things like ordering bloods for tomorrow. Things you 'non-handoverable'. These were jobs that were not know that should have been done during the day. But urgent but they did not feel they could hand over to sometimes, you're just so busy, it doesn't get done.' (P10) the next shift.

\begin{tabular}{|c|c|}
\hline Working atmosphere & $\begin{array}{l}\text { The working atmosphere within the NHS was felt } \\
\text { to be very negative. The working atmosphere in } \\
\text { Australia was thought to be more relaxed than in } \\
\text { the UK. }\end{array}$ \\
\hline
\end{tabular}

Raising concerns ${ }^{\star *} \quad$ F2s were unsure about how to raise concerns and were worried that they might be penalised for doing so.
'The Australian people's personalities are very relaxed and very chilled, so a lot of people have said that that it's a nice environment to work in. In that sense I think it could differ between that and the UK.' (P11)

'How are you supposed to give any of this feedback to the top people, because where on earth are they? I think also sometimes you're worried if you had a concern and you expressed it, that number one, it would fall on deaf ears, and also would you be getting into trouble for expressing concerns?' (P9)

\section{Learning environment}

Learning on the job**

Formal teaching ${ }^{\star \star}$ as a positive part of the learning process. Going abroad was viewed by the F2s as good for on-thejob training.

Australia had a reputation for providing more formal teaching than that which is offered in the UK.
'You can tell people who have been away, and have come back. Just, they're much more confident, they've got much more experience.' (P4)

'One of my friends who is working out in Perth [Australia], has said actually she has like hourly sessions kind of every other week where she'll get bedside teaching. That's way above and beyond what I've had. I don't think I've had bedside teaching beyond what happens on a ward round.' (P13)

Mentorship **

Most of the F2s would have liked to have a mentor, had that been available to them.

'My consultant [in a previous job] was very good in encouraging and looking at options and she was probably the person who gave me the most advice about careers. I found that immensely useful, so I think to have some kind of continuity with someone who could be a mentor would have been probably very helpful.' (P8)

\begin{tabular}{|c|c|c|}
\hline Career advice ${ }^{* *}$ & $\begin{array}{l}\text { Some F2s stated that they had received little or no } \\
\text { career advice. Others were satisfied with the career } \\
\text { advice that they had been given. }\end{array}$ & $\begin{array}{l}\text { 'I think most of the time people expect you to just figure out } \\
\text { on our own what you want to do and get the advice that you } \\
\text { want on your own.' (P12) }\end{array}$ \\
\hline $\begin{array}{l}\text { Balance of service } \\
\text { provision versus learning }\end{array}$ & $\begin{array}{l}\text { Some of the F2s felt that there was a greater } \\
\text { emphasis on service provision than on training. }\end{array}$ & $\begin{array}{l}\text { 'When I was in gen med, there could have been opportunities } \\
\text { to observe lumbar punctures, do more pleural taps and } \\
\text { things. But we just had to do so many discharge letters } \\
\text { and referral forms. And I mean, it just wasn't helpful for our } \\
\text { training.' (P10) }\end{array}$ \\
\hline
\end{tabular}

F2s, foundation year two doctors; NHS, National Health Service. 
Travel was also seen as a potential way of building relationships for future research collaborations.

I think it would probably be good for your career to have a wider experience, wider contacts, certainly academically bigger scope for collaboration. (P16)

Conveyor belt or treadmill of training: Some of the F2s described feeling like they were on a 'conveyor belt' or 'treadmill of training, and felt that post-F2 was a good opportunity to step off for a while.

You are on this conveyor belt, you're 17 and then you've signed up for life. I think, for me, it was just the last couple of years, you realise what you've actually committed to. If I commit to a training programme, that's sixyears or so and after that you are looking at trying to get consultancy posts quite quickly. I would think on that kind of timescale you are thinking about family and mortgages... I don't think you can really travel. This is an opportunity to go away for so long whilst still maintaining your clinical practice. (P6)

E-portfolio: The F2s felt that the e-portfolio was cumbersome to complete and 'too vague to be usefur.

If I can just not have to deal with any portfolio for two years I will be delighted. I think it just detracts so much from any enjoyment that you have... especially with the foundation e-portfolio because they have to design it so generically that some things that they want you to do can be incredibly difficult depending on the particular combination of jobs that you have. (P17)

Further examples of subthemes within the occupational perspective are given in table 3 .

\section{Work group perspective}

Support at work: Other junior doctors were viewed as the most important social relationships at work. Loneliness at work, in particular a lack of contact with other junior doctors, affected their enjoyment at work.

I think also it's been quite a lonely job because you are by yourself a lot of the time. We don't have F1's. We don't have registrars. I didn't realise how much that can affect your job satisfaction... ...because thinking back all the other jobs I've had have been in really big teams and perhaps even when we were busy and it was maybe a bit stressful you could moan about it to somebody else and the loneliness affects you I think... (P1)

Lack of support from seniors was reported in a number of foundation jobs, and affected the F2s' enjoyment at work.

In neurosurgery the registrars weren't very... they're not a very supportive bunch. There's someone suddenly blowing a pupil and you're like, is this person dying? What am I going to do? They'd be like, 'I'm busy, sort it.' (P3)

Bullying from senior doctors was an issue for some of the F2s.

I was sitting flicking through a massive set of notes and then the consultant walks round the corner and goes; 'What are you doing?' and shouts at me in front of all the nurses, everyone on the ward. Then when you get a bit tearful tells you to grow up in front of everyone, very publically. Numerous occasions like that, particularly in surgical jobs. Just being made to feel that you're never good enough and never getting any thanks for what you do. I don't know for sure that that's different in Australia, but from all the feedback I've got from everyone that's in Australia and New Zealand working at the minute it appears to be quite a bit different. (P2)

Task interdependence: F2s did not worry that their leaving would impact on their colleagues, and felt that in some ways it may advantage F2s who chose to stay.

If you look at people leaving as a whole it will make the jobs easier to get in some ways because they'll have less competition. It's different if you're leaving a rota, if you're already in a training position, but it shouldn't affect my colleagues because I've no obligation to be there in that hospital. (P7)

They felt that their going away on a 'gap year' had a small effect when compared with the 'underlying problem of not enough people'.

I maybe haven't thought about it but I'm contributing to that gap...whilst I very much am aware that I am trying to justify it's okay for me to go away and I'm not going to screw everybody over...for next year, I think that the underlying problem is there just not enough people. I think people taking a break is... relatively negligible to the fact that there just aren't enough bodies... (P6)

Working with locums: Working with locums was generally viewed unfavourably.

Sometimes you can get people that are completely new to the specialty and healthcare around the UK or even healthcare at all and that can be more challenging. They're at my level and they're filling up a gap in my rota slot at my level but at the same time I find them depending on me...which can be a bit difficult. (P16)

Additional examples of the ways in which the work group perspective influenced their decision-making are given in table 4 .

\section{Personal life perspective}

Work-life conflict: Some of the F2s described a poor worklife balance in their current NHS roles: 
Table 3 Occupational perspective

Subtheme Details Illustrative quote

The junior doctor contract, role and workload

Salary Salary was unimportant to many of the F2s, to the extent that some did not even know how much they would be paid in their future roles. Others were hoping to have a higher salary, with opportunities for saving money. For many, a higher salary was a 'nice bonus' rather than a reason for going.

\begin{tabular}{|c|c|}
\hline \multirow[t]{2}{*}{$\begin{array}{l}\text { Proposed changes } \\
\text { to contracts in } \\
\text { England** }\end{array}$} & $\begin{array}{l}\text { The proposed changes to junior doctor } \\
\text { contracts in England had unsettled the F2s. } \\
\text { They had mixed feelings about going away } \\
\text { during a time of uncertainty, and concerns } \\
\text { about what it might mean for them if they chose } \\
\text { to return to the UK. }\end{array}$ \\
\hline & $\begin{array}{l}\text { One of the F2s had considered applying to } \\
\text { specialty training in England, but had decided } \\
\text { instead to apply in Australia, partly as a result } \\
\text { of the proposed changes to junior doctor } \\
\text { contracts in England. }\end{array}$ \\
\hline
\end{tabular}

'I think if I worked down there [in England] I'd be totally disheartened and wouldn't really want to continue. Sometimes I think I probably wouldn't want to do this job if I was paid any less... And it'll definitely change my perception if I come back and Scotland's gone the same way, what will I do?' (P2)

'I always wanted to work in London, so if I was applying for CMT1, I would have liked to have apply down South. [But] there was a lot of uncertainty and there's still a lot of uncertainty now about what the contracts are going to be like. I think they have started releasing the provisional contracts now and they look terrible. You've been paid less and you're working a lot more and you're working one in two weekends. It didn't seem like a good thing to trade rather than working somewhere where there is a good work life balance and sunshine and people appreciate what you do for a living in Australia why would I want to move to England?' (P12)
Labour intensity In general, labour intensity was felt to be high in F2 posts, which was exacerbated by understaffing.

F2s had heard that the labour intensity in Australia and New Zealand was lower.

\section{Junior doctor skills}

Transferability of F2s described the development of transferable skills

F2s described the development of transferable
skills which would help them in their future jobs.

Some F2s did not feel adequately prepared to enter specialty training directly.

'We have a lot of staff shortages. Usually there's only one of us on the ward. You feel like you're fighting fires a lot of the time.' (P1)

'From what I hear it's meant to be slightly less intense particularly in A\&E, as I read a few articles. People definitely say you are less stressed because you've just got more people on the shop floor.' (P1)

'I find now I'm less afraid of difficult conversations with families or patients. You have to be better at prioritisation and organising your time. Also trying to delegate to other people and knowing when it's appropriate to call for senior help.' (P1)

'When I see people go and start their CMT [core medical training], they cover CCU [the coronary care unit] and renal on their nightshift. It's funny because at the moment I' $m$ the one calling them about this abnormal ECG [electrocardiogram], but then you think, God, in four months' time I'm the one who is getting called... that sounds awful. I think maybe I am just not quite ready to go into CMT yet.' (P9)

\section{Pursuit of career interests}

Specific clinical job** Some F2s were going away for a specific clinical job, which they could not do in the UK.

$\begin{array}{ll}\begin{array}{l}\text { Further study and } \\ \text { research**}\end{array} & \begin{array}{l}\text { Some of the F2s planned to spend part of } \\ \text { their time after F2 completing further study or } \\ \text { research. }\end{array} \\ & \begin{array}{l}\text { Travel was seen as a potential way of building } \\ \text { relationships for future research collaborations. }\end{array}\end{array}$

Structure of training
'I only wanted to go to New Zealand if I was going to get a particular job in a particular department... I've got a registrar job as a haematologist out there... If I stayed here in the UK I would have had to just apply for CMT, and because haematology is a bit more of an unusual speciality, quite a lot of CMT trainees don't even get to do any haematology, and I would only get to do fourmonths of it anyway.' (P9)

'I am spending the first three months doing a tropical medicine diploma...' (P5)

'I think it would probably be good for your career to have a wider experience, wider contacts, certainly academically bigger scope for collaboration.' (P16) 
Table 3 Continued

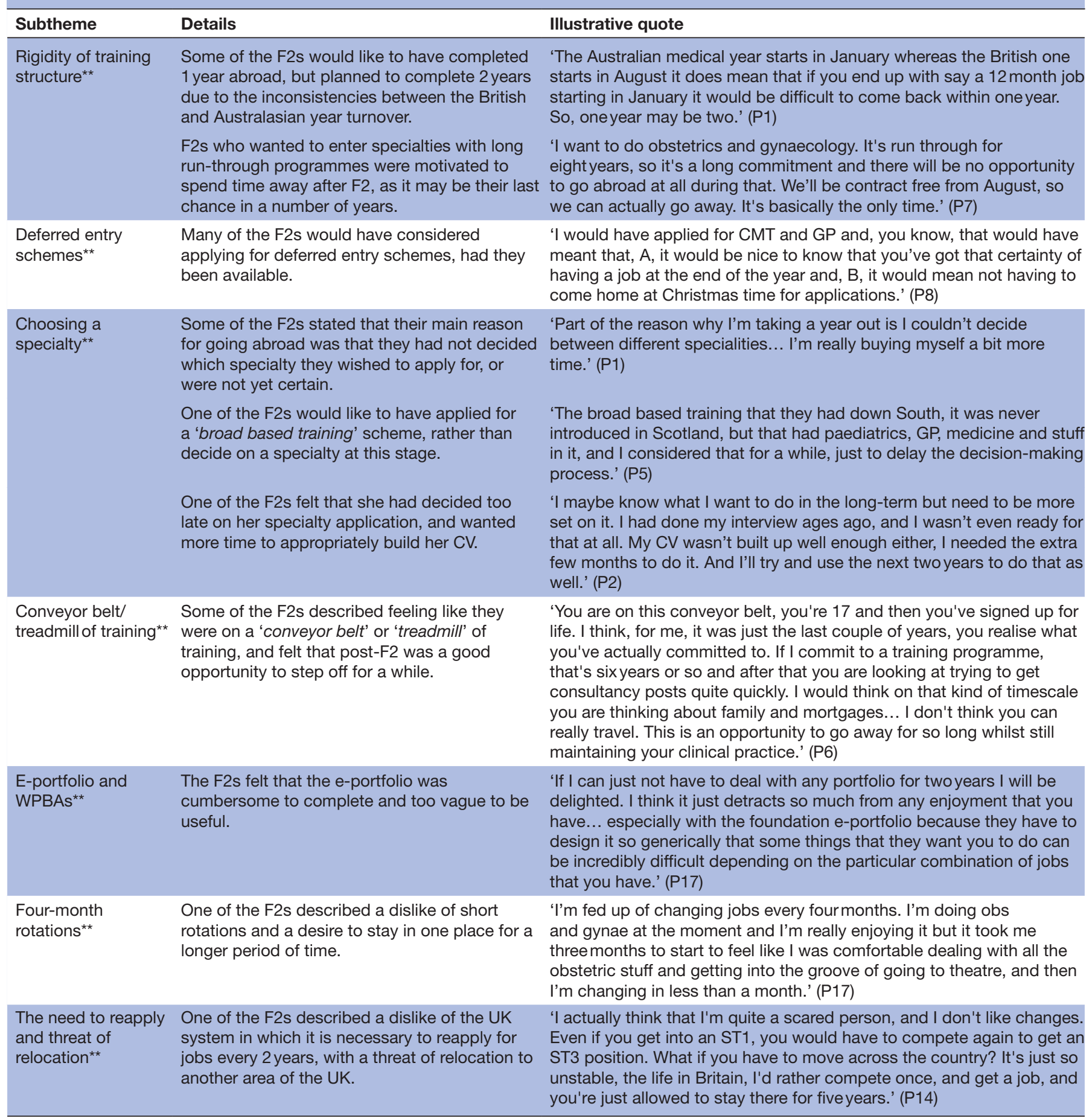

CV, curriculum vitae; F2, Foundation Year 2; F2s, foundation year two doctors; WPBA, workplace-based assessment.

I've missed friends' weddings, I've missed a christening, I missed my grandmother-in-law's funeral because I couldn't get the time off work. (P5)

They described an expectation that there would be less work-life conflict in their roles abroad:

I've spoken to people who are doing A\&E there [in New Zealand], and it's very similar, but, less hours. So, they normally do four days a week, whereas, right now, I'm doing seven. I'm on seven days right now, and
I'm working from either two or three, 'till midnight, every day. Next week, I'm going straight into nights. So that's two weeks that I cannot have any social life. In New Zealand, I can do the job for four days a week, and then have a nice weekend off. (P4)

Work affecting health: The F2s also recounted times when work had negatively affected their own or others' health:

She [another doctor] says the quality of life out there [in Australia] is so much better. She said when she 
Table 4 Work group perspective

\begin{tabular}{ll}
\hline Subtheme & Details \\
\hline Support at work & $\begin{array}{l}\text { Other junior doctors were viewed as the most } \\
\text { important social relationships at work. }\end{array}$ \\
& $\begin{array}{l}\text { Loneliness at work, in particular a lack of } \\
\text { contact with other junior doctors, affected their } \\
\text { enjoyment at work. }\end{array}$
\end{tabular}

Illustrative quote

'You're working with the same big bunch of people. So, you get to know quite a lot of people. It was a really good sized job actually for me, for making friends and creating like a social circle. I actually did quite enjoy it.' (P13)

'I think also it's been quite a lonely job because you are by yourself a lot of the time. We don't have F1's. We don't have registrars. I didn't realise how much that can affect your job satisfaction....... because thinking back all the other jobs I've had have been in really big teams and perhaps even when we were busy and it was maybe a bit stressfu you could moan about it to somebody else and the loneliness affects you I think...' (P1)

Lack of support from seniors affected their enjoyment at work.

Bullying from senior doctors was an issue for some.

Lack of support was not universal. Some of the F2s experienced good senior support at work.

Many F2s had heard that there was good support from senior staff in Australia and New Zealand.

Poor relationships with the nursing staff affected enjoyment at work in at least one case.
"In neurosurgery the registrars weren't very... they're not a very supportive bunch. There's someone suddenly blowing a pupil and you're like, is this person dying? What am I going to do? They'd be like, 'I'm busy, sort it'." (P3)

'I was sitting flicking through a massive set of notes and then the consultant walks round the corner and goes; 'What are you doing?' and shouts at me in front of all the nurses, everyone on the ward. Then when you get a bit tearful tells you to grow up in front of everyone, very publically. Numerous occasions like that, particularly in surgical jobs. Just being made to feel that you're never good enough and never getting any thanks for what you do. I don't know for sure that that's different in Australia, but from all the feedback I've got from everyone that's in Australia and New Zealand working at the minute it appears to be quite a bit different.' (P2)

'From a service provision point of view, I felt very well supported. I've always had seniors around to ask for help, even on my surgical jobs... (P13)

'From what I've heard it is very consultant heavy... I don't think I'll be left as alone as I am here. I think if I'm on call, there will always be a registrar around, and again there will be juniors below me.' (P3)

'The nursing staff wouldn't listen to me. They would then go and get consultants and run everything I did past them. There are some strong characters in that department and it's well known that that is the case. I just clashed with them and I find it quite condescending and made me feel like, that you weren't a doctor, that you are more a medical student because everything you said had to be verified by a consultant.' (P9)

Task

interdependence

F2s did not worry that their leaving would impact on their colleagues, and felt that in some ways it may advantage F2s who chose to stay.

They felt that their going away on a 'gap year' had a small effect when compared with the 'underlying problem of not enough people'.

Use of locums

Working with locums was generally viewed unfavourably.

F2s, foundation year two doctors.

worked here she was always stressed out, quite anxious as well... Then when she went out there she felt more supported and had enough time off to relax. She feels like she's absolutely a completely different person because her work life now doesn't affect her personal life. (P9)
Further examples are given in table 5.

\section{Underlying theme}

One theme spanned many of the different perspectives, and recurred through multiple narratives. This was the theme of 'taking a break'. Examples are below: 
Table 5 Personal life perspective

$\begin{array}{lll}\text { Subtheme Details } & \text { Illustrative quote }\end{array}$

Work-life balance

Work-life conflict
Some of the F2s described a poor worklife balance in their current NHS roles.

The F2s expected there to be less worklife conflict in their roles abroad.
'I've missed friends' weddings, l've missed a christening, I missed my grandmother-in-law's funeral because I couldn't get the time off work.' (P5)

'I've spoken to people who are doing A\&E there [in New Zealand], and it's very similar, but, less hours. So, they normally do fourdays a week, whereas, right now, I'm doing seven. I'm on seven days right now, and I'm working from either two or three, 'till midnight, every day. Next week, I'm going straight into nights. So that's two weeks that I cannot have any social life. In New Zealand, I can do the job for four days a week, and then have a nice weekend off.' (P4)

$\begin{array}{ll}\begin{array}{l}\text { Work affecting } \\ \text { health }^{\star *}\end{array} & \text { The F2s recounted times when work had } \\ & \text { negatively affected their own or others' } \\ \text { health. }\end{array}$

'She [another doctor] says the quality of life out there [in Australia] is so much better. She said when she worked here she was always stressed out, quite anxious as well... Then when she went out there she felt more supported and had enough time off to relax. She feels like she's absolutely a completely different person because her work life now doesn't affect her personal life.' (P9)

Support in resolving Some F2s had heard reports that workwork-life conflict life balance was better supported in Australia, through better handover arrangements and support from consultants.

They perceived a lack of support from the NHS in helping to resolve work-life conflict.
'It's easier to leave on time [in Australia], because you know there's someone there to handover to and your consultant is there saying, go home, is what I've been kind of told.' (P3)

'We know for a fact that we have three vacancies coming up in our rota, and they've done nothing to try and fill them, because in the end they're just going to email round us, rather than getting a locum... and the thing is we do, we do still fill it because we need to, the patients need us.' (P9)

F2s, foundation year two doctors; NHS, National Health Service.

A break from medical training (occupational):

It seems that a lot of FY2's that I know are quite burnt out, to be honest. People are tired of, I don't know if it's tired of working, but... you get into medical school and then it's five or sixyears and straight into foundation training and then you're probably working towards entering medical school for many, many years before you enter medical school. So everyone just seems to need time off. (P12)

A break from being a doctor (occupational):

I think the diploma in tropical medicine will probably be quite full on... but I'm not got people dying around me and having to sort them out, and then equally the sixmonths of travelling is travelling, so I'm not going to be doing any work. (P5)

A break from thinking about career progression (occupational):

It's also a break from having to think about your career too much, especially if you want to go into a competitive speciality. There can always be a pressure on you that it's not just enough to do the day job -you have to get published, you have to do your audits, your posters, your presentations, there's extra courses and working everything into your CV and just all that general stuff, whereas I think if you practice medicine abroad...well, I certainly don't intend on pushing the seriously academic side of my CV too much when I just want to enjoy doing the job. (P17)

A break from the NHS (organisational):

I feel like I should have a break for a year and probably that will make me feel more enthusiastic about working in the NHS again afterwards. (P1)

I would just like to be away from this. And there are times, especially on my previous rota, where the job wasn't as good, and I was working all the horrible hours, and having horrible situations, I was just like, it would be so nice to just not have this. So I think it's just like a nice wee break. (P4)

A break from the UK (personal life):

I think it's about going and exploring a brand new place and having the ideal time in your career to take that break. (P9)

A break from working (personal life): 
CURRENT SITUATION

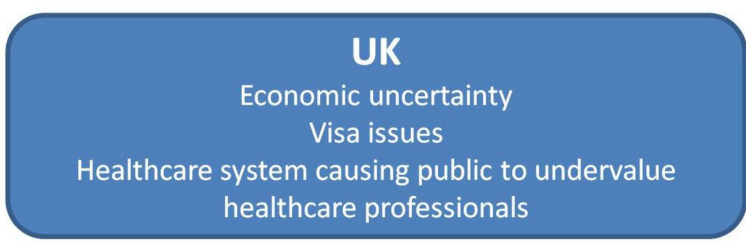

\section{NHS}

Less choice in job location, rota gaps, few perks, undervalued, non-handoverable jobs, negative working atmosphere, difficulty raising concerns, lack of formal teaching, few mentors

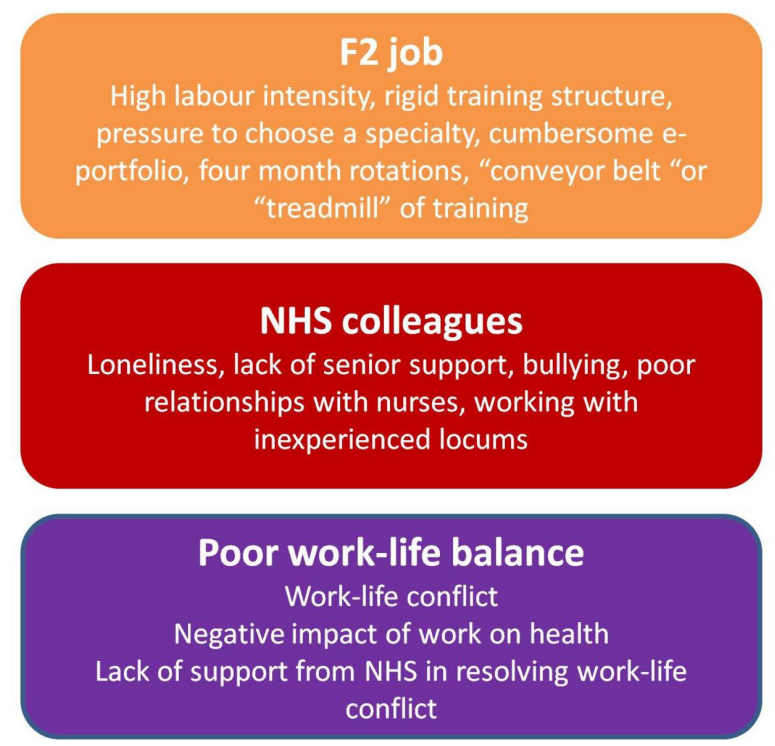

ANTICIPATED BREAK

Other countries

Away from UK's economic uncertainty No visa issues

Public value healthcare professionals

Other healthcare organisations

Choice of job location, well filled rotas, ability to link rota with partner, staff perks, valued, positive working atmosphere, plenty of formal teaching

Junior doctor job abroad Reduced labour intensity, chance to try out other specialties, defer decision to choose specialty, no $\mathrm{e}=$ portfolio requirement, longer rotations available, stepping off the "conveyor belt"

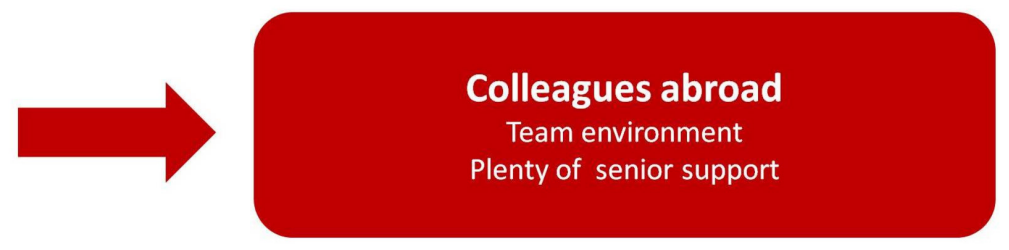

Good work-life balance

Fewer hours at work

Favourable rota patterns

Supported to leave on time

Figure 2 Synthesis of findings, showing the current work situation and anticipated 'break'. F2, Foundation Year 2; NHS, National Health Service.

I'm only moving at the end of August. And the prospect of having more than two weeks of holiday is pretty amazing, actually. So I guess, not a huge, long break, but at least, something that's more than two weeks of holiday, is pretty good. (P14)

A break from the 'hum drum' of life (personal life):

You're opting out of normal life... you're just pleasing yourself and educating yourself and branching out. [At home] you just get bogged down in work and then stuff like having the flat means that you have to maintain the flat. There's bills to pay. There's just the hum drum life and you just you have to deal with it, whereas with travelling you're just so much more free. (P17)

A summary of the findings showing the current work situation and the anticipated 'break' is shown in figure 2.

\section{DISCUSSION}

In this study, we have used a framework provided by Feldman and Ng's 2007 literature review ${ }^{9}$ to explore the reasons that F2 doctors choose to leave UK medicine after their F2 year. The use of this framework has allowed us to explore the breadth of their explicit reasons for leaving. Many of the subthemes identified resonated closely with the framework described by Feldman and Ng, summarised in figure 1. The subthemes for the structural, work group and personal life perspectives were similar to the original framework, indicating similarities between the reasons that F2 doctors choose to leave and those given by other professionals. The subthemes for the organisational and occupational perspectives were, however, quite different from the subthemes in the original framework. This may reflect some of the unique aspects of being an F2 doctor, and of working within the NHS, which may contribute to the decision to move abroad. These are discussed in further detail below.

\section{The structural perspective}

Obtaining work visas for Australia and New Zealand was perceived by participants as straightforward, while UK-trained doctors who were not UK nationals faced difficulties in obtaining a visa to stay in the UK. Given 
the large numbers of junior doctors now leaving the UK, ${ }^{1}$ the UK government could consider special arrangements to allow UK-trained doctors to stay should they wish. Previous research has suggested that in times of financial uncertainty, individuals are more risk averse and unwilling to leave. ${ }^{14}$ In contrast, the F2s in this study felt that the financial uncertainty brought about by the recent Scottish independence referendum and Britain's decision to leave the EU made this a good time to go abroad.

\section{The organisational perspective}

'Feeling valued' was an important concept for the participants. This related to staff perks, and also to working hours and being thanked for doing their job. Something as simple as having a dedicated space to go to during their breaks made doctors feel more valued, though in many hospitals the doctors' mess has been abolished. ${ }^{15}$ This is reiterated in the literature on employee engagement. Seijits and Crim describe the 'Ten Cs of Employee Engagement' as including connect (make employees feel valued), career (provide challenging and meaningful work with opportunities for career advancement), clarity (a clear organisational vision and goals), convey (provide feedback to employees on their performance), congratulate (thank and praise employees), contribute (help employees to understand the value of their contribution), control (give employees opportunities to control the pace and flow of their work), collaborate (provide opportunities to work in teams), credibility (maintain the good reputation of the company) and confidence (have leaders inspire confidence in their employees) ${ }^{16}$ Of these 'Ten Cs', several were brought up by the F2s. For example:

Connect: In Australia... they provide you with parking spaces, food, free tea or coffee... (P2)

Congratulate: It's very rare to get a thank you. (P9)

Collaborate: I think also it's been quite a lonely job be-

cause you are by yourself a lot of the time. (P1)

The working environment and staff morale within the NHS were described as poor: 'It's just a horrible environment to work in' (P8). Snow argues that tackling work climate is the best way to retain more nurses within their jobs. ${ }^{17}$ She suggests addressing the six dimensions of organisational climate, as proposed by Litwin and Stringer. ${ }^{18}$ These include flexibility, responsibility, standards, rewards, clarity and team commitment. ${ }^{18}$ There are a lot of parallels between these criteria and the 10 Cs above. Notably, rewards (which could be as simple as verbal encouragement) were an important way to improve the work climate, and were identified by several F2s in the current study as lacking in the NHS.

The concept of 'non-handoverable job' was interesting, and a possible reason for F2s staying later than their prescribed hours, and was potentially linked to them feeling undervalued. Taylor et al conducted a grounded theory study to investigate the reasons why residents in a Canadian institution chose to stay after their shifts had ended. They found that the dominant rationalisation was 'abiding by cultural norms. ${ }^{19}$ They also found that in a 'relay-team structure', residents were likely to be able to 'pass the baton' and go home, whereas when teams 'did not have the adequate redundancy in manpower', there was a tacit obligation to stay. ${ }^{19}$ In the case of foundation doctors, most handovers were given to a smaller Hospital at Night team, which may help to explain why they felt that it was not possible to hand over all of the remaining jobs.

The F2s made some worrying statements about their fears of raising concerns and about being penalised for doing so. They most often wanted to raise concerns about staffing levels, which is one of the most common whistle-blowing situations. ${ }^{20}$ It is acknowledged that whistle-blowing is still often punished by the medical establishment, and the protection for whistle-blowers remains inadequate. $^{20}$

While the foundation programme is intended to consist of largely workplace-based learning, ${ }^{21}$ the F2s in this study felt that it was important for them to have some formal teaching to support their on-the-job training. Providing a specific study budget was one way in which the F2s understood their training to be valued.

Most of the F2s did not have a mentor but would like to have had one. Mentoring programmes have been shown to improve job embeddedness. ${ }^{22}$ Research on medical students with mentors showed that having a mentor gave a sense of security, gave hope for the future, increased motivation and increased the feeling of belonging in a community. ${ }^{23}$

Some of the F2s identified a lack of formal career advice. This was important as one of the key reasons for going abroad was not deciding on specialty choice, which might conceivably be improved with better career advice. This has previously been identified as a weakness of the foundation programme. ${ }^{21}$

\section{The occupational perspective}

The proposed changes to junior doctor contracts in England provoked mixed emotions among the F2s. The changes were first proposed in July 2013, but negotiations stalled on multiple occasions, with the result that junior doctors in England undertook industrial action in December 2015, March 2016 and April 2016. Further negotiations in May 2016 led to a proposed change in the contract. ${ }^{10}$ These proposals made many of the Scottish F2s in this study wonder if they would return to the UK, due to fears that the changes would affect Scottish contracts in the future, and availability of specialty training jobs in Scotland due to competition from English trainees.

The F2s described the development of multiple transferable skills. This is important because development of such skills is associated with higher levels of job mobility. ${ }^{24}$ In some ways, the skills that they had developed had prepared them better for further foundation jobs, rather than necessarily preparing them to enter specialty training. The transition to core medical training was viewed as particularly daunting. The aim of the 
foundation programme is to "bridge the gap between undergraduate and specialty training, ${ }^{21}$ but to date there have been no studies to evaluate how effectively it does this.

Further study and research were cited as reasons for 'taking time out', as was having to choose a specialty at an early stage. The foundation programme evaluation identifies flexibility within the programme, as well as improved career information and advice, as important recommendations for the future of the foundation programme. ${ }^{21}$

F2s often cited a desire to step off the 'treadmill' or 'conveyor belt' of training. They expressed a desire for individualised programmes, and viewed taking a 'year out' as a way of providing an individual element for themselves. The foundation programme evaluation highlighted a 'lack of flexibility' in the foundation programme, and a need to address this in the future. ${ }^{21}$

The foundation e-portfolio was viewed as a box-ticking exercise rather than as a useful opportunity to improve their skills. This concurs with previous research, which finds that foundation doctors consider the assessments to be 'excessive, onerous and not valued.' ${ }^{21}$

\section{The work group perspective}

Loneliness at work, a lack of support from seniors, dysfunctional relationships and bullying at work were all cited as reasons for lack of enjoyment in their foundation jobs. These are reflected in the literature. For example, loneliness, reported by junior doctors in previous studies, ${ }^{25}$ has been associated with depression. ${ }^{26}$ The foundation programme evaluation (2011) describes a 'repeated theme of some trainees being asked to practise beyond their level of competence and without adequate levels of supervision. ${ }^{, 21}$ Furthermore, a questionnaire study of 594 junior doctors found that $37 \%$ reported being bullied in the previous year. ${ }^{27}$ Most of the F2s reported having heard about a utopic Australasian system in which there are higher staffing levels, good support and a strong senior presence.

Bishop and Scott purport that task interdependence promotes stronger commitment to the organisation as a whole. ${ }^{28}$ The structure of UK training prevents F2 doctors working interdependently with others. The structure of training is such that they must leave their current role at the end of the year, and as such they will never be leaving their current colleagues 'in the lurch'. This may help to explain why none of the F2s expressed any guilt regarding leaving the NHS.

In keeping with previous research, the use of locums was associated with poor satisfaction at work. ${ }^{29}$ However, rota gaps with no locum cover were associated with even greater levels of dissatisfaction in the current study.

\section{The personal life perspective}

The desire to seek a better work-life balance was frequently cited by the F2s as a reason to leave the UK. Some of the F2s also identified a negative impact of their work-life on their health. Long numbers of consecutive days and nights worked have previously been shown to be associated with a poor work-life balance. ${ }^{30}$

\section{'Taking a break'}

The original framework, provided by Feldman and $\mathrm{Ng}$, explored reasons why people may choose to change their job. In the case of F2s, we identified an underlying theme- a desire not to change their job but simply to 'take a break' from various aspects of their lives. This theme may represent a level of burnout in junior doctors, who are at once trying to take a break from the UK, from working, from the 'hum drum', from medical training, from being a doctor, from thinking about career progression and from the NHS. High levels of burnout have been reported previously, with between $40 \%$ and $76 \%$ of junior doctors estimated to have experienced burnout. ${ }^{31}$ Many of the F2s do, however, state a clear intention to return to the UK after 'taking a break', bringing with them new skills and experience from their time abroad.

\section{Limitations}

This study explores the in-depth views of Scotland-based F2 doctors regarding their training experience and their ideas about junior doctor jobs abroad. We have explored their explicit reasons for leaving, as well as some factors known to increase job mobility, in order to uncover some of the hidden reasons for junior doctors leaving the NHS. There have not been any other qualitative studies exploring this phenomenon. We have used a constructivist approach, and have therefore produced results which do not attempt to predict the future, but instead explore the intricacies of decision-making, ${ }^{32}$ and provide a springboard for further areas of research.

We used a pre-existing framework to explore doctors' reasons for leaving the UK. It is possible that through using this framework, we have overlooked some of the other reasons that F2s may have had for leaving. We have tried to minimise this risk by starting with very open questions about why they chose to leave and aiming specifically to find reasons that did not fit fully within the framework. We were open to exploring any reasons that did not fit within or contradicted the predefined framework with as much vigour as those that seemed to resonate with it.

All of the participants were working as F2s in Scotland. This was deliberate: At the time of this research, there was a great deal of uncertainty surrounding proposed changes to junior doctor contracts in England. ${ }^{10}$ There were anger and frustration relating to the proposed changes, ${ }^{10}$ and we felt that interviews with English trainees were likely to be very focused on junior doctor contracts, and lacking in some of the other rich data that we have uncovered. Unlike positivist research, these results cannot be claimed to be generalisable, but instead may be transferable to other contexts. For example, issues such as lack of career advice or mentorship programmes may not apply to every area in the UK, or the world, but may apply to some. Although only F2s working in Scotland were interviewed, we aimed to obtain as diverse a range of views as possible by interviewing F2s from all four regions, of different ages, a mix 
of genders and with different specialty interests and destinations in mind. The age range of volunteers was narrow (24-27), and did not include any graduate entrants, despite our attempts to recruit as diversely as possible. This might feasibly be because older F2s may be less likely to consider leaving the UK.

Junior doctors may have wanted to present a certain image of themselves to the researcher. We attempted to ameliorate this by using a non-threatening environment (participants were interviewed in their own homes via a video link) and by ensuring anonymity. The researcher was also a doctor who had chosen to move abroad, thus reducing any threat of judgement towards participants.

Constructivism acknowledges that the researchers are biased. We do not try to minimise the bias, but instead reflect on the impact of the researchers' preconceptions on the data. ${ }^{32}$ Four of the researchers are doctors, three of whom work in the NHS and one who has moved abroad. We therefore carry our own experiences of working in the NHS environment, and feelings about moving away, which may add richness to the data. Many of the comments made by the F2s resonated with the report authors, and we were able to connect and relate to the F2s, especially when their experiences matched our own. We did not seek to simply support our preconceived views, but also to create new understanding about the driving forces behind F2s' decisions to leave.

\section{Future research}

This study has opened many avenues for possible future research. We were unable to recruit graduate entrants to this study, and their views could be useful sought in a further study. It would be interesting to follow the F2s into their new roles abroad, to find out if their expectations were met. It would be useful to explore their decision-making when deciding whether to return to the UK. The questions asked in this study could be posed from a more positivist perspective, perhaps by using this study as the basis for a questionnaire sent out to all F2s throughout the UK. We could consider conducting a similar study in other parts of the UK, to determine whether any of the results are transferable to other contexts. Finally, we could design, implement and evaluate a strategy based on the results of this study to encourage F2s to stay or come back to the UK.

\section{CONCLUSIONS}

The Feldman and Ng's framework provides a helpful template for exploring the reasons that F2 doctors choose to leave UK medicine. Many of their reasons are similar to those given by any professional considering a change in their job (availability of jobs elsewhere; a desire to improve work-life balance; or a desire to enjoy better job perks). However, working within the NHS as an F2 doctor brought specific challenges: the rigidity of the training structures; the requirement to make a choice of specialty within the F2 year; exposure to workplace bullying; and difficulties in raising concerns. Despite these challenges, most of the F2s did not view their decision to leave as making a permanent job change, but as a temporary break from their current working lives.

Acknowledgements The authors thank Dr JCM van Hammel, Dr G Kearney and Professor T Dornan for their helpful comments on the draft manuscript.

Contributors SES, VRT, LMP, AHL and JM met in person and online during the planning stages of this work, and all contributed to the research design. SES conducted all of the interviews. SES analysed all of the interview transcripts, and VRT, LMP and JM checked two themes each for consistency. SES prepared the manuscript for submission and VRT, LMP, AHL and JM revised the manuscript before submission.

Funding This work was funded by a Scottish Medical Education Research Consortium grant.

Competing interests None declared.

Patient consent Not required.

Ethics approval The need for full ethical approval was waived by the research ethics committees in South East Scotland, East of Scotland, North of Scotland and West of Scotland.

Provenance and peer review Not commissioned; externally peer reviewed.

Data sharing statement Additional data are available by emailing sam.smith@ ed.ac.uk.

Open Access This is an Open Access article distributed in accordance with the Creative Commons Attribution Non Commercial (CC BY-NC 4.0) license, which permits others to distribute, remix, adapt, build upon this work non-commercially, and license their derivative works on different terms, provided the original work is properly cited and the use is non-commercial. See: http://creativecommons.org/ licenses/by-nc/4.0/

(c) Article author(s) (or their employer(s) unless otherwise stated in the text of the article) 2018. All rights reserved. No commercial use is permitted unless otherwise expressly granted.

\section{REFERENCES}

1. The UK Foundation Programme Office. F2 career destination

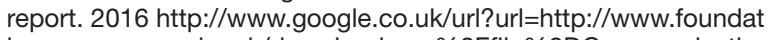
ionprogramme.nhs.uk/download.asp\%3Ffile\%3DCareers_destina tion_2016.pdf\&rct=j\&frm =1\&q=\&esrc=s\&sa=U\&ved=0ahUKEwjZ3m4IJHVAhUEOSYKHauPAuQQFggTMAA\&usg=AFQjCNGc_VmgtVpN1QwCOH3ta0QHUg11Q

2. Kenny C. 5000 doctors a year considering leaving the UK to emigrate abroad, Pulse. 2014 http://www.pulsetoday.co.uk/home/finance-andpractice-life-news/5000-doctors-a-year-considering-leaving-the-ukto-emigrate-abroad/20007366.article

3. Kenny C. Desperate bid to fill training places falls flat as $12 \%$ of GP posts remain unfilled. Pulse. 2014 http://www.pulsetoday.co.uk/yourpractice/practice-topics/education/desperate-bid-to-fill-trainingplaces-falls-flat-as-12-of-gp-posts-remain-unfilled/20008297.article

4. British Medical Association. Struggle to fill GP vacancies in Scotland. BMA News. 2015 http://bma.org.uk/news-views-analysis/ news/2015/march/struggle-to-fill-gp-vacancies-in-scotland

5. The Scottish Government. Drive to recruit GP trainees. $2016 \mathrm{http}: / /$ news.scotland.gov.uk/News/Drive-to-recruit-GP-trainees-2859.aspx

6. Sharma A, Lambert TW, Goldacre MJ. Why UK-trained doctors leave the UK: cross-sectional survey of doctors in New Zealand. J R Soc Med 2012;105:25-34.

7. Moss PJ, Lambert TW, Goldacre MJ, et al. Reasons for considering leaving UK medicine: questionnaire study of junior doctors' comments. BMJ 2004;329:1263.

8. Guba EG, Lincoln YS. Competing paradigms in qualitative research. In: Denzin NK, Lincoln YS, eds. Handbook of qualitative research. Thousand Oaks, CA: Sage, 1994.

9. Feldman DC, Ng TWH. Careers: mobility, embeddedness, and success. J Manage 2007;33:350-77.

10. British Medical Association. How the junior and consultant contract negotiations unfolded. BMA News. 2016 https://www.bma.org.uk/ collective-voice/influence/key-negotiations/terms-and-conditions/ junior-and-consultant-contract-home/negotiations-background 
11. Vogt WP, Statistics D. Methodology: A Nontechnical Guide for the Social Sciences. London: Sage, 1999.

12. Strauss AL, Corbin JE. Basics of qualitative research: techniques and procedures for developing grounded theory. Thousand Oaks, CA: Sage Publications Inc, 1998.

13. King N. Template analysis. In: Symon G, Cassell C, eds. Qualitative methods and analysis in organizational research: a practical guide. London: SAGE Publications, 1998.

14. Leana CR, Feldman DC. The psychology of job loss. In: Research in personnel and human resources management, 1994:12, 271-302.

15. Lees P. The doctors' mess is dead, long live the doctors' mess. 2016 https://www.fmlm.ac.uk/news-opinion/the-doctors\%E2\%80\%99mess-is-dead-long-live-the-doctors $\%$ E2\%80\%99-mess: Faculty of Medical Leadership and Management

16. Seijits GH, Crim D. What engages employees the most or, the ten C's of employee engagement. Ivey Business Journal 2006;70:1.

17. Snow JL. Enhancing work climate to improve performance and retain valued employees. J Nurs Adm 2002;32:393-7.

18. Litwin GH, Stringer RA. Motivation and organizational climate. Boston: Harvard University Press, 1968.

19. Taylor TS, Nisker J, Lingard L. To stay or not to stay? A grounded theory study of residents' postcall behaviors and their rationalizations for those behaviors. Acad Med 2013;88:1529-33.

20. Bolsin S, Pal R, Wilmshurst P, et al. Whistleblowing and patient safety: the patient's or the profession's interests at stake? $J R$ Soc Med 2011;104:278-82.

21. Collins J. Foundation for excellence: an evaluation of the foundation programme: Medical Education England, 2010. http://www. nhsemployers.org/your-workforce/retain-and-improve/bettertraining-better-care/foundation-for-excellence-an-evaluation-of-thefoundation-programme
22. Noe RA, Greenberger DB, Wang S. Mentoring: what we know and where we might go. In: Research in personnel and human resources management, 2002:21, 129-73.

23. Kalén $\mathrm{S}$, Ponzer $\mathrm{S}$, Silén $\mathrm{C}$. The core of mentorship: medical students' experiences of one-to-one mentoring in a clinical environment. Adv Health Sci Educ Theory Pract 2012;17:389-401.

24. Fugate M, Kinicki AJ, Ashforth BE. Employability: a psychosocial construct, its dimensions, and applications. J Vocat Behav 2004;65:14-38

25. de Lasson L, Just E, Stegeager N, et al. Professional identity formation in the transition from medical school to working life: a qualitative study of group-coaching courses for junior doctors. BMC Med Educ 2016;16:165.

26. Jaremka LM, Andridge RR, Fagundes CP, et al. Pain, depression, and fatigue: loneliness as a longitudinal risk factor. Health Psychol 2014;33:948-57.

27. Quine L. Workplace bullying in junior doctors: questionnaire survey. BMJ 2002;324:878-9.

28. Bishop JW, Scott KD. An examination of organizational and team commitment in a self-directed team environment. J Appl Psychol 2000;85:439-50.

29. Davis-Blake A, Broschak JP, George E. Happy together? how using nonstandard workers affects exit, voice, and loyalty among standard employees. Acad Manage J 2003;46:475-85.

30. Brown M, Tucker P, Rapport F, et al. The impact of shift patterns on junior doctors' perceptions of fatigue, training, work/life balance and the role of social support. Qual Saf Health Care 2010;19:e36.

31. McCray LW, Cronholm PF, Bogner HR, et al. Resident physician burnout: is there hope? Fam Med 2008;40:626-32.

32. Charmaz K. Constructing grounded theory. London: Sage, 2006. 